\title{
Hepatitis C virus epidemiology and prevention in Polish and Swiss population - similar and contrasting experiences
}

\author{
Benjamin Sakem', Kazimierz Madaliński², Urs Nydegger' ${ }^{1}$ Małgorzata Stępień2, \\ Paulina Godzik2 , Agnieszka Kołakowska², Lorenz Risch', Martin Risch', Karolina Zakrzewska2,3, \\ Magdalena Rosińska² \\ ${ }^{1}$ Labormedizinisches Zentrum Dr. Risch, Liebefeld, Switzerland \\ ${ }^{2}$ National Institute of Public Health - National Institute of Hygiene, Warsaw, Poland \\ ${ }^{3}$ Department of Epidemiology, Medical University of Warsaw, Poland
}

Sakem B, Madaliński K, Nydegger U, Stępień M, Godzik P, Kołakowska A, Risch L, Risch M, Zakrzewska K, Rosińska M. Hepatitis C virus epidemiology and prevention in Polish and Swiss population - similar and contrasting experiences. Ann Agric Environ Med. 2016; 23(3): 425-431. doi: 10.5604/12321966.1219181

\begin{abstract}
Objective. The aim of the study was to review available data on HCV in Poland and Switzerland, in order to compare the two European countries with respect to epidemiological situation and efficiency of the response systems.

Materials and method. A search of registries, published and grey literature was performed to assemble data on prevalence, rate of detection of new cases, identified risk factors for transmission, mortality due to HCV, prevalence of HCC and the consequent liver transplantations, as well as data on treatment in Poland and Switzerland.

Results. Overall, the prevalence of anti-HCV antibodies was similar, not exceeding $1 \%$. However, the major transmission routes of HCV infections were different: medical procedures in Poland and drug injections in Switzerland. By combining the available information it was also possible to demonstrate important differences in efficiency of the response systems. There was approximately 1 new diagnosis per 100 estimated undiagnosed cases in the population in Poland per year, compared to 6 in Switzerland, and the treatment rate per 100 estimated active infections was 2 and 4, respectively.

Conclusions. Scaling up of the diagnosis and treatment is necessary in both countries; however, the means to achieve this might differ, taking into account the higher concentration of the infections in risk groups in Switzerland than in Poland.
\end{abstract}

\section{Key words}

hepatitis C, acute and chronic HCV infection, epidemiological data, Poland and Switzerland, consequences of infection, access to treatment

\section{INTRODUCTION}

Hepatitis C is recognized worldwide as one of the biggest epidemic problems; although the global number of infected persons tends to decline [1]. Distribution of hepatitis C displays considerable variation across regions and countries, including important differences between countries in Europe $[1,2,3]$. Globally, blood-borne transmissions occur mainly during iatrogenic exposures and the injection of drugs, and these two routes are believed to contribute to the majority of the new infections worldwide $[4,5]$. However, whereas medical procedures, in particular unsafe injections, may be responsible for the majority of infections in developing countries; injecting drugs is the main transmission route of the Hepatitis C virus (HCV) in many developed countries, and the prevalence of $\mathrm{HCV}$ among people who inject drugs (PWID) remains high $[6,7]$. High prevalence is also observed among migrants and minority groups [8], and men who have sex with men (MSM), especially the Human Immunodeficiency Virus (HIV)-positive MSM [9].

Moreover, the incidence of chronic hepatitis $\mathrm{C}$ complications, such as cirrhosis, liver failure, or hepatocellular carcinoma (HCC), is expected to still rise in Europe in the

Address for correspondence: Kazimierz Madaliński, National Institute of Public Health - National Institute of Hygiene, Chocimska 24, 00-791 Warsaw, Poland E-mail: kmadalinski@pzh.gov.pl

Received: 22 December 2015; accepted: 01 March 2016 coming years if the current policies, especially related to screening, are not revised [10]. With the advent of new potent therapies, public health action to increase testing uptake as well as the access to the new therapeutic options is crucial [11]. While the need for coordinated response is acknowledged in view of the expected large future burden of the disease, the epidemiological situation may differ, requiring adaptation of the public health interventions. In addition, comparability of epidemiological information across countries is often questioned. The data originate from different surveillance systems and are sensitive to prophylactic policies, such as screening implemented on the national level [12]. Comparisons between countries or areas, or even comparisons over time necessary to monitor progress, may pose a challenge.

Two European countries with different socio-economical profiles were selected: Poland (PL) and Switzerland $(\mathrm{CH})$, to examine potential differences and similarities in the epidemiological situation and the needs for public health interventions. The population of Poland amounts to $38.5 \mathrm{mln}$, while that of Switzerland $-8.2 \mathrm{mln}$. The diverse economic situation in the two countries influenced and continues to influence financial resources for medical services. As an example, Poland experienced late approval of disposable medical equipment (1985-1988), and the change from dry sterilizers into autoclaves in hospitals (1995-2006) and outpatients clinics (2000) lasted longer than in Switzerland, 
where the safe decontamination of medical devices has been standard since the early 1970s. Too long exploitation of the machines due to financial constraints of the Polish health care system may constitute an additional problem [13].

\section{OBJECTIVE}

The aim of this study is to compare the current epidemiological situation regarding the $\mathrm{HCV}$ infection in two countries, Switzerland and Poland, combining available evidence and based on summary indicators, which can be helpful in international comparisons and discuss their utility in wider context of hepatitis $\mathrm{C}$ public health response systems. This will facilitate exchange of good practices and identify what lessons can be learned from Switzerland to Poland and vice versa.

\section{MATERIALS AND METHOD}

The study was undertaken within the framework of the Swiss-Polish Cooperation Programme 'Prevention of HCV Infections'. Published literature, surveillance data and grey literature on the epidemiology and burden of HCV infection in Poland and Switzerland were reviewed to assemble data on prevalence, rate of detection of new cases, identified risk factors for transmission, mortality due to $\mathrm{HCV}$, prevalence of HCC and the consequent liver transplantations, as well as data on treatment. The following terms were used for the literature search in the PubMed database: hepatitis $\mathrm{C}$ AND (Poland OR Switzerland) AND (incidence, prevalence, mortality, risk factors, HCV diagnosis, transplants, viremia or genotype). The search was restricted to articles published after the year 2000. Finally, 794 relevant published articles and surveillance reports relating to HCV in Poland and/or Switzerland were considered for the study. In both countries, the archives of agencies responsible for surveillance, coordination of transplantations, cancer registries, drugs control, life statistics offices, as well as health and life insurance institutions, were scrutinized. Their websites were searched for publications/ reports or interactive databases allowing the retrieval of relevant data. Surveillance data reported to State agencies from the year 2000 were analyzed to determine the number of persons newly reported on the basis of a positive test result for HCV infection (www.pzh. gov.pl; www.bag.admin.ch). Both Switzerland and Poland have a comprehensive surveillance system registering all new cases of HCV, confirmed with HCV-RNA or Western blot test, not excluding resolved infections. The mortality rates were extracted from the national census data using the International Statistical Classification of Diseases and Related Health Problems (ICD-10) code B17.1, B18.2 (acute/chronic hepatitis C) and C22.0 (HCC). Numbers of liver transplants were obtained from transplantation registries. Finally, where deemed necessary, the agencies were contacted to confirm data availability or ambiguities. In addition, available evidences were reviewed with respect to response measures accessible in each country, and why and when they were implemented. Basic epidemiological indicators in both countries were extracted or calculated. These included incidence of acute hepatitis $\mathrm{C}$, anti-HCV prevalence, the rate of detection of $\mathrm{HCV}$ cases per total population, reported exposures, as well as the burden of illness indicators. The latter included mortality from HCV disease, liver transplantation rate and access to treatment (rate of treatment). The following indicators were then addressed, according to case-based surveillance: proportion of acute cases among newly-diagnosed cases; proportion of cases attributed to specific risk groups (e.g. PWID, MSM, hemophilia patients, dialysis patients).

Additionally, composite indicators relating detected cases, complications and the number of treated patients to the existing epidemiological situation were addressed. The outcome events were divided by the estimated number of people affected by HCV. The following denominator populations were defined:

1) people who were infected and either still have an active infection or might have eliminated the virus spontaneously or via treatment (approximated by anti-HCV positive population);

2) people with active infection (HCV-RNA positive population);

3) undiagnosed population with past or present infection markers (HCV-RNA positive and/or anti-HCV positive).

By making this distinction, it was hoped to capture the population potentially at risk of developing complications or dying due to HCV-induced illness (population 1); effective detection and care system will ensure timely treatment and reduction of unfavourable outcomes, such as HCC, liver transplant or deaths; the total population in need of treatment (population 2) and the population who needs to be diagnosed (population 3). The following indicators are proposed:

a) detection indicator, defined as the annual number of detected cases per number of estimated undiagnosed cases in a population;

b) treatment indicator, defined as the proportion of treated persons to the estimated number of prevalent cases of active infection;

c) indicators of mortality, defined as the annual HCV mortality rate among anti-HCV positive cases.

\section{RESULTS}

Basic epidemiological indicators. During the 11 year period (2002-2012) a number of serological surveys were conducted to establish the prevalence of HCV infections in both countries, including 32 published studies in Poland and 71 in Switzerland. The studies addressed key groups, where the prevalence is likely to be high (PWID, hemophilia patients, long-term patients, including those on dialysis and patients diagnosed with HCC), general population proxy groups (general hospital admissions, pregnant women, health care personnel and organ donors) and blood donors. The general population prevalence was comparable in both countries, with substantial variation across different studies. The presented study reports the most recent available estimate covering at least several regions in the country.

The estimated anti-HCV prevalence was $0.86 \%$ in Poland and $0.71 \%$ in Switzerland (Tab. 1) $[14,15]$. The prevalence of HCV-RNA (active infection) was approximately $0.6 \%$ in both countries $[16,17,28]$. The distribution of genotypes in Poland among prevalent cases in 2003-2012 confirmed the predominance of genotype 1 (79.4\%), followed by 
Table 1. Epidemiological indicators of HCV infection in Poland and Switzerland

\begin{tabular}{|c|c|c|c|c|}
\hline \multirow[t]{2}{*}{ Indicator } & \multirow{2}{*}{ PL } & \multicolumn{3}{|c|}{$\mathrm{CH}$} \\
\hline & & source & value & source \\
\hline Anti-HCV prevalence in general population and number of anti-HCV positive cases & $0.86 \%(270,000)$ & {$[14]$} & $0.71 \%(60,000)$ & [15] \\
\hline $\begin{array}{l}\text { Percent of HCV-RNA positive patients among anti-HCV positives in general population and estimated number of } \\
\text { HCV-RNA positive cases }\end{array}$ & $63 \%(162,000)$ & {$[16]$} & $64 \%(38,400)$ & [17] \\
\hline HCV prevalence among first-time blood donors & $0,3 \%$ & [18] & $0.08 \%$ & [18] \\
\hline \multicolumn{2}{|l|}{ Annual number of new HCV diagnoses and rate of new diagnoses per 100,000 (2012) } & \multirow{3}{*}{ [19] } & & \multirow{3}{*}{ [20] } \\
\hline Total & $2292(5.95)$ & & 1744 (21.6) & \\
\hline Acute & $47(0.12)$ & & $60(0.74)$ & \\
\hline Annual number of liver transplants (2011) & 300 & {$[21]$} & 109 & {$[22]$} \\
\hline Percent of liver transplants due to HCV and estimated number of liver transplants due to HCV & $27.8 \%(83)$ & {$[23]$} & $21-30 \%$ & [2] \\
\hline \multicolumn{2}{|l|}{ Annual number of deaths and mortality per 100,000 due to hepatitis C (2012) } & \multirow[b]{2}{*}{ [19] } & & \multirow[b]{2}{*}{ [24] } \\
\hline Total & $217(0.56)$ & & $17(0.22)$ & \\
\hline Incidence rates (mortality) per 100,000 of primary liver cancer (C22) (2012), crude rates & $5.8(5.4)$ & {$[25]$} & $10.5(8.9)$ & {$[25]$} \\
\hline Percent of HCC attributed to HCV & $65.60 \%$ & {$[26]$} & $85 \%$ & {$[27]$} \\
\hline
\end{tabular}

genotype 3 (13.8\%) and genotype 4 (4.9\%) [29]. In contrast, in Switzerland, $46 \%$ of genotype 1, $8.4 \%$ of genotype 2, 27\% of genotype 3 and $9 \%$ of genotype 4 was recorded [17]. It should be noted that the high prevalence of genotype 3 in Switzerland is typical for Western country with a high fraction of injection drug users among whom this genotype tends to be more common [30]. The reported incidence rate of acute hepatitis $\mathrm{C}$, respectively, is 6.5 and 3.5 times higher in $\mathrm{CH}$ than in $\mathrm{PL}(\mathrm{p}<0.0001)$. The proportion of acute cases among all reported cases was $2.0 \%$ in $\mathrm{PL}$ and $3.6 \%$ in $\mathrm{CH}$ $(\mathrm{p}=0.0037)$. In recent years, there were approximately 300 liver transplants in PL per year. Taking into account the proportions of liver transplants due to $\mathrm{HCV}$ in PL (27.8\%) [23], the annual number of HCV related transplants may be estimated at $83\left(=27.8 \%{ }^{*} 300\right)$ [21] or $2.2 / 1 \mathrm{mln}$ population. In $\mathrm{CH}$, the respective number is 26 or $3 / 1 \mathrm{mln}[2,22]$. As modeled based on mortality data [25], primary liver cancer incidence is estimated at 5.8 per 100,000 in PL and 10.5 in $\mathrm{CH}$. In specific studies, $65.6 \%$ of HCC in PL [26] and $85 \%$ in $\mathrm{CH}$ [27] were attributed to $\mathrm{HCV}$ which, when extrapolated to HCC incidence, would translate into HCV-related HCC incidence rate of 3.8 and 8.9 per 100,000 in PL and $\mathrm{CH}$, respectively. Direct (i.e. not attributed to HCC) mortality due to hepatitis C (ICD-10 codes B17.1, B18.2) in 2011 was lower than the estimated HCC mortality -0.56 and 0.22 per 100,000 in PL and CH, respectively $[19,20]$ (Tab. 1).

Risk factors and transmission routes. Risk factors and history of exposures is reported through surveillance system in both countries. The predominant presumptive transmission route in $\mathrm{CH}$ remains injecting drug use (57\%), whereas this group accounts only for $5.8 \%$ of reported infections in PL. The risk factors confirmed in analytical studies in PL include male gender, transfusions (before 1992), frequent surgical procedures and i.v. drug use (all with moderate effect sizes, OR $<7$ ) [16]. High association of $\mathrm{HCV}$ with injecting drug use was noted in Switzerland, with remarkable effect size (OR 78.9) [38] (Tab. 2). This is further supported by high sero-prevalence among people who inject drugs, then among dialyzed and hemophilia patients $[32,36]$ (Tab. 2). Additionally, recent data point to the rapid spread of
HCV among men who have sex with men (MSM), especially HIV-infected MSM in CH [9]. No studies on HCV spread among HIV-positive MSM in PL could be found.

Diagnosis and treatment indicators. The diagnosed fraction is higher in $\mathrm{CH}$ than PL, $49 \%$ versus $10.7 \%[38,40]$. Moreover, the treatment rate with respect to total population is higher in $\mathrm{CH}$ (1,100 persons, 1.4 per 1 million inhabitants) than in $\mathrm{PL}$ (3,202, 0.8 per 1 million) [41] (Tab. 3). Moreover, the cumulative rate of ever treated patients per prevalent cases was higher in $\mathrm{CH}$ than in PL (9.5\% vs $0.7 \%$ ) [42]. Efficiency of diagnosis was measured by undiagnosed prevalence and the annual number of detected cases per number of undiagnosed prevalent cases (Tab. 4).

The undiagnosed fraction in PL was estimated at $89.3 \%$, translating into an undiagnosed prevalence of $0.77 \%$ or 241,110 persons. The number of new diagnoses per prevalent undiagnosed cases was approximately 1 per 100 annually. In contrast, in $\mathrm{CH}$ the undiagnosed fraction was estimated at $51 \%$, undiagnosed prevalence $-0.36 \%$ or 30,600 persons, and the number of new diagnoses per prevalent undiagnosed cases -6 . The annual number of treatments per 100 prevalent active infections cases was 2 in PL and 4 in $\mathrm{CH}$ (Tab. 4). The total HCV related mortality (including HCV related HCC mortality per 1,000 anti-HCV positive cases per year in the population) was higher in $\mathrm{CH}$ (11) than in PL (5).

\section{DISCUSSION}

This study summarizes available epidemiological information on HCV epidemics in two countries with different historical and economic background: Poland (PL) and Switzerland (CH). It was noted that despite some important similarities, e.g. comparable prevalence, there are significant differences in the factors driving the epidemics, in particular the role of injecting drugs users in the spread of the infection differs, and the effectiveness of the health care systems to detect and manage infections to prevent $\mathrm{HCV}$ related complications and deaths. As a consequence, the recommended approaches towards public health response in these two countries may differ. 
Table 2. HCV risk groups and risk factors in Poland and Switzerland

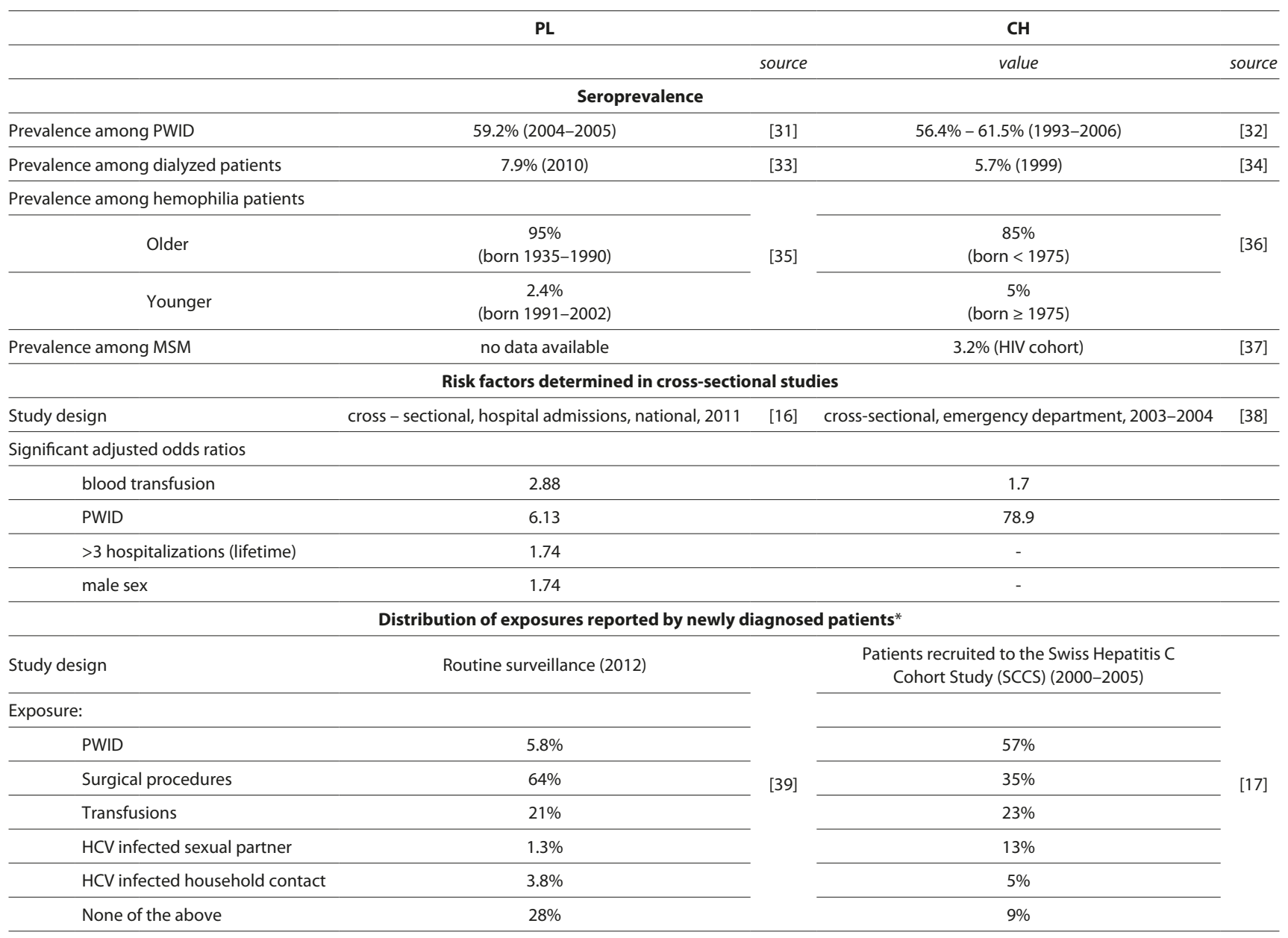

* many persons reported more than one exposure

Table 3. Diagnosis and treatment indicators in Poland and Switzerland

\begin{tabular}{|c|c|c|c|c|}
\hline & PL & & $\mathrm{CH}$ & \\
\hline & value & source & value & source \\
\hline Diagnosed fraction (\% diagnosed among anti-HCV positive population) & $10.70 \%$ & {$[40]$} & $49 \%$ & [38] \\
\hline Annual number of patients commencing treatment & $3202(2011)$ & National Health Fund programme monitoring data & $1100(2013)$ & [41] \\
\hline Cumulative rate of ever treated patients per prevalent cases & $0.7 \%$ & {$[42]$} & $9.5 \%$ & [42] \\
\hline
\end{tabular}

Table 4. Composite response indicators

\begin{tabular}{|c|c|c|c|}
\hline Indicator & Formula & $P L$ & $\mathrm{CH}$ \\
\hline $\begin{array}{l}\text { Annual number of newly-diagnosed HCV cases } \\
\text { per } 100 \text { undiagnosed persons in population }\end{array}$ & $\begin{array}{l}\text { Numerator: annual number of new diagnoses (Tab. } 1) \times 100 \text {; denominator: undiagnosed fraction (Tab. } 2 \text { ) } \\
\times \text { estimated number of anti-HCV positive cases in population (Tab. } 1 \text { ) }\end{array}$ & 1 & 6 \\
\hline $\begin{array}{l}\text { Annual number of newly-treated per } 100 \mathrm{HCV} \text { - } \\
\text { RNA positive cases in population }\end{array}$ & $\begin{array}{l}\text { Numerator: number of newly-treated patients per year (Tab. } 2) \times 100 \text {; denominator includes the } \\
\text { estimated number of HCV-RNA cases in population (Tab. } 1 \text { ) }\end{array}$ & 2 & 4 \\
\hline $\begin{array}{l}\text { Annual HCV and HCV related HCC mortality rate } \\
\text { per } 1,000 \text { anti-HCV positive cases in population }\end{array}$ & $\begin{array}{l}\text { Numerator: crude mortality rate due to HCV (per } 100,000+\text { proportion } \mathrm{HCC} \text { due to } \mathrm{HCV} \times \text { crude mortality } \\
\text { rate due to HCC per 100,000; denominator: anti-HCV prevalence (\%) (Tab. 1) }\end{array}$ & 5 & 11 \\
\hline
\end{tabular}

The characteristic feature of the epidemic in $\mathrm{CH}$, as in other Western European countries, is the concentration of $\mathrm{HCV}$ among PWID (57\% of newly-diagnosed cases). On the other hand, persons infected by this route of transmission represent only a small proportion of cases in Poland. This could be an exposure ascertainment artifact in PL, considering the higher reluctance of disclosing the drug use status due to stigmatization of drug users. However, the difference is supported by the results of analytical studies. Although injecting drugs is a risk factor for $\mathrm{HCV}$ infection in both countries, the effect size was much larger in $\mathrm{CH}$ : 78.9 vs 6.13 in PL. Furthermore, a higher rate of HCV was noted among 
blood donors in PL. Persons from highly exposed-groups, such as PWID or persons with recent sexual exposures, are advised not to donate blood and the prevalence among blood donors may represent the lower limit of general population prevalence. Therefore, the high rates in Poland point to a significant spread outside the high risk groups.

Both surveillance data and specific studies regarding HCV epidemiology in PL indicate an important transmission of the virus in medical settings $[16,43,44,45]$. Transfusions in the past (before 1992) and major surgical procedures were implicated in over two-thirds of cases reported through surveillance. Nonetheless, a large proportion of newlydiagnosed patients were not able to identify any of the major risk factors. Whereas the sterilization processes of medical equipment used by hospitals have gradually improved and at present all hospitals use proper autoclave procedures and central organization, the situation in the past might have led to infection of a significant number of patients. Moreover, breaches in injection procedures implemented in health care facilities could also contribute to HCV spread, as evidenced by 6 outbreaks in medical settings that were investigated as a consequence of the occurrence of a cluster of acute cases [39]. In contrast, the Swiss HIV cohort study indicates that HCV infection incidence decreased in PWID, remained stable in heterosexuals, and increased 18-fold in MSM during this century (indicating again that the highest transmission rates may be limited to specific groups) and was mainly unrelated to medical procedures [46].

The reported rate of newly detected $\mathrm{HCV}$ cases tends to be higher in CH than in PL: 20 in CH versus 5.7 per 100,000 in PL. It is possible that the surveillance systems differ in terms of completeness of case ascertainment. However, the PL system was assessed in 1998, revealing a high proportion of reported cases [45]. Also, the surveillance systems are quite similar, relying on clinical and laboratory reporting. Thus, the differences most probably reflect the differences in HCV detection rates. This is further supported by the fact that $\mathrm{HCV}$-infected people are more likely to be diagnosed at an acute stage in $\mathrm{CH}$. Taking into account that the diagnosed fraction and the detection rate per 100 prevalent undiagnosed cases in the population might be higher in $\mathrm{CH}$ than in PL, it can be assumed that the efficiency of screening systems currently differs between PL and $\mathrm{CH}$.

The system efficiency may be related to a high concentration of the epidemic among people who inject drugs. The Swiss system offers universal screening to all PWID (www.checkyour-love-life.ch). This targeted strategy may be appropriate in the country where the HCV infection concentrates in high risk groups [47]. In Poland, the situation is complicated by the wide spread of the epidemic in the general public, as discussed above. Improvement of HCV testing access for the general public should be recommended in PL, potentially as a part of routine health check-ups. Further research is needed to establish the cost-efficiency of such a procedure. Access to antiviral therapies, in terms of the number of treated patients (per prevalent cases), was better in $\mathrm{CH}$ than in PL, but might be judged unsatisfactory in both countries. However, significant improvements both in PL and in $\mathrm{CH}$ are expected with new therapeutic programmes basing on interferon-free treatment (Direct Antiviral Agents) [48, 49].

On the other hand, although there was some evidence that the diagnosis and treatment systems are more efficient in $\mathrm{CH}$ than in PL, lower rates of HCC and liver transplants were also noted in PL, when related to the number of existing $\mathrm{HCV}$ cases. The $\mathrm{HCV}$ infection in $\mathrm{CH}$ concerns, on average, the younger population (about $60-65 \%$ of cases constitute young adults in the age group 20-39 [22]) than in PL. The average age at HCV diagnosis in PL is 44 years, and a substantial proportion of diagnosed cases (47\% in 2012) is 50 years or older at diagnosis [19]. It is possible that the relatively low rate of HCV deaths and complications in PL is caused by a higher competing mortality from other causes. On the other hand, HCC incidence may be under-ascertained in Poland as the histopathological confirmation rate is low, and the final classification of a substantial proportion of liver cancers remain undetermined [25].

Large data gaps were identified, including testing patterns (testing rates and profile of the tester) and access to treatment (e.g. by drug use status, socio-economic, or demographic indicators). Additionally, little is known about the HCV incidence among migrants and men who have sex with men. Migrants from countries with high HCV prevalence have a significant impact on the epidemiology of the diseases in their destination countries [3, 50, 51] like Switzerland [52, 53]. Due to limited data available, it was not possible to address the issue of uncertainty of different indicators, which very often compelled the assumption that certain proportions established on limited subgroups of patients will still hold true for the entire population. Further investigations are needed, as well as better data collection, to refine these assumptions. However, the authors were able to propose several composite indicators, based on existing data, which allow the capturing of differences in the epidemic and effectiveness of the response systems in the two countries.

\section{CONCLUSION}

It was concluded that the scaling-up of diagnosis and treatment is necessary in both countries. Even if the indicators of diagnosis and treatment in Switzerland are higher, they still remain unsatisfactory as less the 10 persons out of 100 requiring treatment are, in fact, treated each year. The public health systems aim to detect and treat infections, stop transmissions due to non-sterile injections and other medical and non-medical procedures, prevent transmission via sharing drug injecting equipment, or unsafe sexual behaviors. The efficiency of different interventions will depend, among others, on the extent of concentration of the epidemic in specific subpopulations. For example, screening policies targeted to high risk groups, such as injecting drug uses, will be highly effective if infections are mostly limited to this group, as in Switzerland, but could miss the point in the epidemics driven in e.g. by unsafe medical procedures, as is the case in Poland. A similar situation was described for the HIV epidemic, for which the World Health Organization (WHO) developed a classification, including generalized, concentrated and lowlevel epidemic with different recommended approaches to curb it. A similar approach seems reasonable for $\mathrm{HCV}$, and could help to better tailor prevention to country needs.

\section{Acknowledgements}

The study was supported by the Swiss-Polish Cooperation Programme 'Prevention of HCV Infections' grant from Switzerland through the Swiss Contribution to the Enlarged European Union (KIK 35). The Programme is co-financed by 
the Polish Ministry of Health. The authors declare that they have no conflicts of interest and sponsorship, and declare adherence to ethical recommendations.

\section{REFERENCES}

1. Gower E, Estes C, Blach S, Razavi-Shearer K, Razavi H. Global epidemiology and genotype distribution of the hepatitis $\mathrm{C}$ virus infection. J Hepatol. 2014; 61: 45-57 [PMID: 25086286 DOI: 10.1016/j. jhep.2014.07.027].

2. Bruggmann P, Berg T, Øvrehus AL, Moreno C, Brandão Mello CE, Roudot-Thoraval F, et al. Historical epidemiology of hepatitis $\mathrm{C}$ virus (HCV) in selected countries. J Viral Hepat. 2014; 21 Suppl 1: 5-33 [PMID: 24713004 DOI: 10.1111/jvh.12247].

3. Cornberg M, Razavi HA, Alberti A, Bernasconi E, Buti M, Cooper C, et al. A systematic review of hepatitis $C$ virus epidemiology in Europe, Canada and Israel. Liver Int 2011; 31 Suppl 2: 30-60 [PMID: 21651702 DOI: 10.1111/j.1478-3231.2011.02539.x].

4. Hatia RI, Dimitrova Z, Skums P, Teo EY, Teo CG. Nosocomial hepatitis $\mathrm{C}$ virus transmission from tampering with injectable anesthetic opioids. Hepatology 2015 Mar 22. [PMID: 25808284 DOI: 10.1002/hep.27800].

5. Alter MJ. HCV routes of transmission: what goes around comes around. Semin Liver Dis. 2011; 31: 340-346 [PMID: 22189974 DOI: 10.1055/s0031-1297923].

6. Rondy M, Wiessing L, Hutchinson SJ, Matheï C, Mathis F, Mravcik $\mathrm{V}$, et al. Hepatitis $\mathrm{C}$ prevalence in injecting drug users in Europe, 1990-2007: impact of study recruitment setting. Epidemiol Infect. 2013; 141: 563-572 [PMID: 22595549 DOI: 10.1017/S0950268812000921].

7. Palmateer N, Hutchinson S, McAllister G, Munro A, Cameron S, Goldberg D, Taylor A. Risk of transmission associated with sharing drug injecting paraphernalia: analysis of recent hepatitis C virus (HCV) infection using cross-sectional survey data. J Viral Hepat. 2014; 21: 25-32 [PMID: 24329854 DOI: 10.1111/jvh.12117].

8. Sharma S, Carballo M, Feld JJ, Janssen HL. Immigration and Viral Hepatitis. J Hepatol. 2015; In press [PMID: 25962882 DOI: 10.1016/j. jhep.2015.04.026].

9. Burchell AN, Gardner SL, Mazzulli T, Manno M, Raboud J, Allen VG, et al. Hepatitis $\mathrm{C}$ virus seroconversion among HIV-positive men who have sex with men with no history of injection drug use: results from a clinical HIV cohort. Can J Infect Dis Med Microbiol. 2015; 26: 17-22 [PMID: 25798149].

10. Deuffic-Burban S, Deltenre P, Buti M, Stroffolini T, Parkes J, Mühlberger $\mathrm{N}$ et al. Predicted effects of treatment for HCV infection vary among European countries. Gastroenterology 2012; 143: 974-985 [PMID: 22863764 DOI: 10.1053/j.gastro.2012.05.054].

11. Wedemeyer H, Duberg AS, Buti M, Rosenberg WM, Frankova S, Esmat $\mathrm{G}$, et al. Strategies to manage hepatitis $\mathrm{C}$ virus (HCV) disease burden. J Viral Hepat. 2014; 21 Suppl 1: 60-89. [PMID: 24713006 DOI: 10.1111/ jvh.12249].

12. European Centre for Disease Prevention and Control. Hepatitis B and C surveillance in Europe. 2012. Stockholm: ECDC; 2014.

13. Jakimiak B, Röhm-Rodowald E, Staniszewska M. [Sterilization in Polish hospitals]. [Article in Polish] OPM Ogolnopolski Przeglad Medyczny 2006; 11: 32-6.

14. Godzik P, Kołakowska A, Madaliński K, Stepień M, Zieliński A, Góralewska A, et al. [Prevalence of anti-HCV antibodies among adults in Poland-results of cross-sectional study in general population]. [Article in Polish] Przegl Epidemiol. 2012; 66: 575-580 [PMID: 23484383].

15. Prasad LR, Masserey Spicher V, Kammerlander R, Zwahlen M. Hepatitis $\mathrm{C}$ in a sample of pregnant women in Switzerland: seroprevalence and socio-demographic factors. Swiss Med Wkly 2007; 137: 27-32 [PMID: 17299665].

16. Flisiak R, Halota W, Horban A, Juszczyk J, Pawlowska M, Simon K. Prevalence and risk factors of HCV infection in Poland. Eur J Gastroenterol Hepatol. 2011; 23:1213-1217 [PMID: 22002000 DOI: 10.1097/MEG.0b013e32834d173c].

17. Prasad L, Spicher VM, Zwahlen M, Rickenbach M, Helbling B, Negro F; Swiss Hepatitis C Cohort Study Group. Cohort Profile: the Swiss Hepatitis C Cohort Study (SCCS). Int J Epidemiol. 2007; 36: 731-737 [PMID: 17693458].

18. Directorate for the Quality of Medicines and Health Care of the Council of Europe. Trends and Observations on the Collection, Testing and Use of Blood and Blood Components in Europe (2001-2008). Council of Europe Publishing, Strasbourg, 2014
19. Parda N, Henszel L, Stepien M. Hepatitis C in Poland in 2012. Przegl Epidemiol. 2014; 68: 265-269 [PMID: 25135512].

20. Datendetails Hepatitis C. Meldepflichtige Infektionskrankheiten Schweiz und Fürstentum Liechtenstein [Article in German], cited 2015-06-09; available from: URL: http://www.bag.admin.ch/k_m_ meldesystem/00733/00813/index.html.

21. [Information bulletin Poltransplant 2015;1] [Article in Polish] cited 2015-06-09. Available from: URL: http://www.poltransplant.org.pl/ biuletyn_2015.html.

22. Monitoring Transplantationsgesetz. Bundesamt für Gesundheit, Sektion Transplantation und Fortpflanzungsmedizi. Zusammenfassende Ergebnisse des Monitorings 2004-2013; 8. Dezember 2014, [Article in German], cited 2015-06-09. Available from: URL: http://www.bag. admin.ch/transplantation/00692/00941/index.html.

23. Krawczyk M, Grat M, Barski K, Ligocka J, Antczak A, Kornasiewicz O, et al. 1000 liver transplantations at the Department of General, Transplant and Liver Surgery, Medical University of Warsaw-analysis of indications and results. Pol Przegl Chir. 2012; 84: 304-312 [PMID: 22842743 DOI: $10.2478 /$ v10035-012-0051-y].

24. World Health Organization Regional Office for Europe. European Detailed Mortality Database, cited 2015-06-10. Available from: URL: http://data.euro.who.int/dmdb/

25. Ferlay J, Soerjomataram I, Ervik M, Dikshit R, Eser S, Mathers C et al. GLOBOCAN 2012 v1.0, Cancer Incidence and Mortality Worldwide: IARC CancerBase No. 11 [Internet]. Lyon, France: International Agency for Research on Cancer; 2013. Cited 2015-06-09. Available from: http:// globocan.iarc.fr, accessed on 19/05/2015.

26. Grat M, Kornasiewicz O, Lewandowski Z, Skalski M, Zieniewicz K, Paczek L, Krawczyk M. The impact of surgical technique on the results of liver transplantation in patients with hepatocellular carcinoma. Ann Transplant. 2013; 18: 448-59 [PMID: 24008493 DOI: 10.12659/ AOT.884005].

27. Kuske L, Mensen A, Müllhaupt B, Negro F, Semela D, Moradpour D et al. Swiss Hepatitis C Cohort Study. Characteristics of patients with chronic hepatitis $C$ who develop hepatocellular carcinoma. Swiss Med Wkly 2012; 142: w13651 [PMID: 22869395 DOI: 10.4414/ smw.2012.13651].

28. The Swiss Hepatitis C Cohort Study (SCCS), cited 2015-06-09. Available from URL: www.swisshcv.ch

29. Panasiuk A, Flisiak R, Mozer-Lisewska I, Adamek A, Tyczyno M et al. Distribution of HCV genotypes in Poland. Przegl Epidemiol. 2013; 67: 11-16, 99-103 [PMID: 23745369].

30. Wiessing L, Ferri M, Grady B, Kantzanou M, Sperle I, Cullen KJ, et al. EMCDDA DRID group. Hepatitis C virus infection epidemiology among people who inject drugs in Europe: a systematic review of data for scaling up treatment and prevention. PLoS One 2014; 9: e103345 [PMID: 25068274 DOI: 10.1371/journal.pone.0103345].

31. Rosinska M, Sieroslawski J, Wiessing L. High regional variability of $\mathrm{HIV}, \mathrm{HCV}$ and injecting risks among people who inject drugs in Poland: comparing a cross-sectional bio-behavioural study with case-based surveillance. BMC Infect Dis. 2015; 15: 83 [PMID: 25879904 DOI: 10.1186/s12879-015-0828-9].

32. Dubois-Arber F, Balthasar H, Huissoud T, Zobel F, Arnaud S, Samitca $S$ et al. Trends in drug consumption and risk of transmission of HIV and hepatitis C virus among injecting drug users in Switzerland, 1993-2006. Euro Surveill. 2008; 13: 1-6 pii: 18881 [PMID: 18761964].

33. Rutkowski B, Lichodziejewska-Niemierko M, Grenda R, Czekalski S, Durlik M, Bautembach S. [Report on the renal replacement therapy in Poland - 2010] [Article in Polish]. Polish renal registry of the Polish Society of Nephrology, Gdansk, 2013.

34. Ambuhl PM, Binswanger U, Renner EL. [Epidemiology of chronic hepatitis $\mathrm{B}$ and $\mathrm{C}$ among dialysis patients in Switzerland] [Article in German]. Schweiz Med Wochenschr 2000; 130: 341-348 [PMID: 10763211].

35. Windyga J, Grabarczyk P, Stefanska E, Buczma A, Szczepanik AB, Klukowska A et al. [Prevalence of HCV, HBV and HIV infections among severe Polish haemophiliacs] [Article in Polish]. Przegl Epidemiol. 2008; 62: 415-423 [PMID: 18807489].

36. Brand B, von der Weid N. Haemophilia registry of the medical committee of the swiss haemophilia society. Hamostaseologie. 2009; 29 Suppl 1: 16-18 [PMID: 19763362].

37. Dubois-Arber F, Jeannin A, Lociciro S, Balthasar H. Risk reduction practices in men who have sex with men in Switzerland: serosorting, strategic positioning, and withdrawal before ejaculation. Arch Sex Behav. 2012; 41: 1263-1272 [PMID: 22083656 DOI: 10.1007/s10508011-9868-4]. 
38. Russmann S, Dowlatshahi EA, Printzen G, Habicht S, Reichen J, Zimmermann $\mathrm{H}$. Prevalence and associated factors of viral hepatitis and transferrin elevations in 5036 patients admitted to the emergency room of a Swiss university hospital: cross-sectional study. BMC Gastroenterol. 2007; 7: 5 [PMID: 17280611].

39. Stępień M, Rosińska M. Hepatitis C oubreaks in Poland in 2003-2013. Medical procedures as a dominant route of HCV transmission. Przegl Epidemiol. 2015; 69:465-472 [PMID: 26519841].

40. Hartleb M, Gutkowski K, Zejda JE, Chudek J, Wiecek A. Serological prevalence of hepatitis $B$ virus and hepatitis $C$ virus infection in the elderly population: Polish nationwide survey-PolSenior. Eur J Gastroenterol Hepatol. 2012; 24: 1288-1295 [PMID: 22864260].

41. Wandeler G, Dufour JF, Bruggmann P, Rauch A. Hepatitis C: a changing epidemic. Swiss Med Wkly. 2015; 145: w14093 [PMID: 25658972 DOI: 10.4414/smw.2015.14093].

42. Lettmeier B, Mühlberger N, Schwarzer R, Sroczynski G, Wright D, Zeuzem S, Siebert U. Market uptake of new antiviral drugs for the treatment of hepatitis C. J Hepatol. 2008; 49: 528-536 [PMID: 18682313 DOI: $10.1016 /$ j.jhep.2008.04.021].

43. Chlabicz S, Grzeszczuk A, Prokopowicz D. Medical procedures and the risk of iatrogenic hepatitis $\mathrm{C}$ infection: case-controlled study in northeastern Poland. J Hosp Infect. 2004; 58: 204-209 [PMID: 15501335].

44. Szaflik J, Belzecka-Majszyk A. [Patients with HBV, HCV and HIV antigens--medical management, surgical procedures, equipment sterilization principles] [Article in Polish]. Klin Oczna 2003; 105: 448-452.

45. Mazurek J, Hutin Y, McNutt LA, Morse DL. Evaluation of hepatitis C surveillance in Poland in 1998. Epidemiol Infect. 2002; 129: 119-125 [PMID: 12211578].

46. Alipour A, Rezaianzadeh A, Hasanzadeh J, Rajaeefard A, Davarpanah MA. Sexual Transmission of Hepatitis C Virus Between HIV Infected
Subjects and Their Main Heterosexual Partners. Hepat Mon. 2013; 13: e13593 [PMID: 24348647 DOI: 10.5812/hepatmon.13593].

47. Zuure FR, Urbanus AT, Langendam MW, Helsper CW, van den Berg CH, Davidovich U, Prins M. Outcomes of hepatitis C screening programs targeted at risk groups hidden in the general population: a systematic review. BMC Public Health. 2014; 14: 66 [PMID: 24450797 DOI:10.1186/1471-2458-14-66].

48. [Advanced remuneration of new medicines for the treatment of chronic hepatitis C] Article in German [Internet]. 2015-09-02 [cited 2015-1105] Available from: http://www.bag.admin.ch.

49. [Therapeuthic Programmes/Non-oncology diseases/Treatment of chronic hepatitis C] Article in Polish [Internet]. 2015-07-01 [cited 2015-11-05] Available from: http://www.mz.gov.pl.

50. Markov PV, van de Laar TJ, Thomas XV, Aronson SJ, Weegink CJ, van den Berk GE et al. Colonial history and contemporary transmission shape the genetic diversity of hepatitis $C$ virus genotype 2 in Amsterdam. J Virol. 2012; 86: 7677-7687 [PMID: 22573865 DOI: 10.1128/JVI.06910-11].

51. Esteban JI, Sauleda S, Quer J. The changing epidemiology of hepatitis $\mathrm{C}$ virus infection in Europe. J Hepatol. 2008; 48: 148-162 [PMID: 18022726].

52. Razavi H, Waked I, Sarrazin C, Myers RP, Idilman R, Calinas F, et al. The present and future disease burden of hepatitis $\mathrm{C}$ virus (HCV) infection with today's treatment paradigm. J Viral Hepat. 2014; 21 Suppl 1:34-59. [PMID: 24713005 DOI: doi: 10.1111/jvh.12248].

53. Müllhaupt B, Bruggmann P, Bihl F, Blach S, Lavanchy D, Razavi H et al. Modeling the health and economic burden of hepatitis $\mathrm{C}$ virus in Switzerland. PLoS One 2015; 10:e0125214. [PMID: 26107467 DOI: 10.1371/journal.pone.0125214]. 